\title{
STRATEGI MEWUJUDKAN KEMANDIRIAN SEKTOR FINANSIAL LOKAL MELALUI SUSTAINABILITAS LEMBAGA KEUANGAN MIKRO SYARIAH (BAITUL MAAL WATAMWIL, BMT)
}

\author{
Yus Indra \\ STIE Indonesia Banking School \\ Email: yusindra@yahoo.com
}

\begin{abstract}
Sustainability of Sharia Microfinance Institution or BMT is influenced by institutional sustainability, financial sustainability and external support. Aspects of sustainability are organizations, policies and procedures, internal control systems, tasks and authorities, financing risk management, human resources and outreach of products and activities, aspects affecting financial sustainability are capital adequacy, asset quality, liquidity, profitability and efficiency, while the factors affecting the external support are Laws and Regulations, Supervisory of authority and Associate Agencies (APEX). To build sustainability BMT then must attention to aspects mentioned above. This research is motivated by previous studies on financial sustainability of micro finance institutions, through best practice approach in financial institution generally conducted research to get, test and reconstruct to other aspects of sustainability of microfinance institution, that is aspect related to institution. This is due to the limited research that discusses institutional sustainability. Based on the research, it can be concluded that sustainability of BMT is influenced by institutional sustainability, financial sustainability and external support, but in the implementation stage it is necessary to re-implement the management based on best practice approach of banking
\end{abstract}

Keyword : sustainability, governance

\begin{abstract}
Abstrak. Sustainabilitas Lembaga Keuangan Mikro Syariah atau BMT dipengaruhi oleh sustainabilitas kelembagaan (institutional sustainability), sustainabilitas keuangan (financial sustainability) dan dukungan eksternal. Aspek yang mempengaruhi sustainabilitas adalah organisasi, kebijakan dan prosedur, sistem pengendalian internal, tugas dan kewenangan, manajemen risiko pembiayaan, Sumber Daya Insani dan keterjangkauan produk dan aktivitas. Aspek yang mempengaruhi sustainabilitas keuangan adalah kecukupan permodalan, kualitas aset, likuiditas, profitabilitas dan efisiensi, sedangkan faktor yang mempengaruhi dukungan eketernal adalah Undang-Undang dan regulasi, otoritas pembinaan dan pengawasan dan lembaga pengayom (APEX). Penelitian ini dilatarbelakangi oleh penelitian terdahulu mengenai sustainabilitas keuangan lembaga keuangan mikro, melalui pendekatan best practice perbankan dilakukan penelitian untuk merekontruksi kembali hasil penelitian terhadap aspek-aspek dari sustainabilitas lembaga keuangan mikro, yaitu aspek-aspek yang terkait dengan kelembagaan (institutional). Hal ini mengingat masih terbatasnya penelitian yang membahas mengenai sustainabilitas kelembagaan (institutional sustainability). Berdasarkan penelitian diperoleh hasil bahwa sustainabilitas BMT dipengaruhi oleh sustainabilitas kelembagaan (institutional sustainability), sustainabilitas keuangan (financial sustainability) dan dukungan eksternal, namun dalam tahap implementasinya perlu dilakukan pentatakelolaan kembali berdasarkan pendekatan best practice perbankan.
\end{abstract}

Kata Kunci : sustainabilitas, tatakelola

\section{PENDAHULUAN}

Banyak kendala yang harus dihadapi untuk membangun dan menciptakan kemandirian sektor finansial lokal melalui sistem perbankan yang ada saat ini, khususnya dalam rangka menghadapi pasar bebas sektor keuangan MEA tahun 2020. Rendahnya kesadaran terhadap kesiapan pasar bebas keuangan MEA tahun 2020 dan upaya pembenahan yang masih berjalan lambat, berdampak terhadap akses kepada lembaga keuangan (inklusifitas) yang juga rendah (kecuali P.Jawa) atau potensi sektor keuangan nasional yang besar masih tetap terabaikan.

Dibandingkan beberapa negara ASEAN lainnya inklusifitas dan pendalaman (deepening) sektor perbankan Indonesia jauh lebih rendah, hal ini terindikasi dari rasio Kredit terhadap GDP, dimana Thailand 
mencapai sebesar $147 \%$, Singapura sebesar $126 \%$ dan Malaysia sebesar 120\%, sementara Indonesia hanya sebesar $36,5 \%$. Hal ini mengindikasikan bahwa sektor keuangan di negara-negara yang rasionya lebih dari 100\% memiliki potensi pasar yang terbatas dan persaingan yang sangat ketat, sebaliknya negara dengan rasio yang kecil memiliki potensi pasar yang besar. Hukum pasar akan berlaku, negara dengan rasio tinggi akan melakukan ekspansi pasar keuangannya ke negara yang rasionya rendah, ketika diberlakukannya pasar bebas sektor keuangan ASEAN tahun 2020 nanti.

Indonesia sebagai negara yang mayoritas Islam selain memiliki potensi kekuatan ekonomi yang besar, juga memiliki sistem ekonomi syariah yang komprehesif dengan prinsip kemaslahatan dan berkeadilan bagi seluruh rakyat Indonesia. Bagian dari sistem ekonomi tersebut salah satunya adalah lembaga keuangan mikro syariah (LKMS) atau yang dikenal sebagai BMT (Baitul Maal wat Tamwil), BMT merupakan sistem ekonomi dan keuangan yang sekaligus dapat menyatukan kepentingan ekonomi dengan kepentingan sosial dalam masyarakat. .

\section{METODE PENELITIAN Disain Penelitian}

Teknik pengumpulan

data menggunakan kuesioner atau data primer. Pemilihan responden menggunakan cara proporsive sampling yaitu pengambilan sampel dengan menetapkan ciri yang sesuai dengan tujuan penelitian. Obyek penelitian adalah BMT dari anggota Induk Koperasi Syariah (Inkopsyah).

\section{Pengujian dan Analisis}

a. Uji statistik deskriptif berupa : nilai ratarata, modus, standar deviasi, rata-rata standar error, varian dan analisis tabulasi.

b. Uji validitas adalah untuk mendapatkan indikator apakah kuesioner tersebut mampu mengukur apa yang harus diukur (Trihendradi, 2013).

c. Uji Reliabilitas adalah untuk mendapatkan indikator konsistensi atau handal (reliable) atas hasil pengukuran, walaupun digunakan untuk mengukur berkali-kali (Trihendradi, 2013). d. Uji Runs disebut uji sampel (tunggal) untuk memeriksa keacakan (random).

e. Uji Kolmogorov-Smirnov adalah menguji kecocokan (goodness of fit) data ordinal pada suatu distribusi tertentu (normal, uniform, poisson, eksponensial).

f. Uji t statistik satu arah untuk menguji perbedaan rata-rata sebuah sampel dengan nilai tertentu suatu populasi atau nilai hipotesisnya.

g. Geometric Mean adalah nilai rata-rata yang menunjukan tendensi, untuk mengetahui hasil penilaian individu dari responden dan menentukan hasil pendapat pada satu kelompok (Saaty, 2013 ).

\section{Tahapan Peneltian}

Hasil kajian pustaka dan pengumpulan data dari pakar dan praktisi akan mendapakan kerangka model penelitian. Selanjutnya dilakukan pendekatan secara Best Practices untuk mendapatkan kerangka model Implementasi sustainabilitas BMT

\section{HASIL DAN PEMBAHASAN}

Berdasarkan hasil analisa penelitian sebagaimana telah diuraikan, perlu dilakukan rekontruksi kembali dengan mengikuti best practice perbankan. Hasil rekonstruksi tersebut menjadi kerangka penerapan atau implementasi sustainabilitas BMT sebagai bagian dari strategi untuk mewujudkan kemandirian sektor finansial lokal. Penerapan sustainabilitas BMT dapat dirumuskan sebagaimana pada Gambar 1 .

Adapun penjelasan faktor-faktor implementasi sustainabilitas BMT sebagai berikut :

\section{Tata Kelola (Good Governance)}

Untuk menjadi BMT yang sustainable perlu adanya pondasi yang kuat, yaitu penerapan faktor-faktor yang berkaitan dengan tata kelola sebagai berikut :

a. Perangkat Organisasi

1) Infrastruktur organisasi : Rapat Anggota Tahunan (RAT) yang diadakan secara berkala setiap tahun, serta mendorong misi untuk menegakkan nilai-nilai muamalah dan syariah, seperti : nilai-nilai Illahiyah, kemaslahatan, 
keberimbangan, kebenaran dan keberkahan, serta mewujudkan visinya sebagai agen rahmatan lil'alamin untuk mensejahterakan masyarakat melalui nilai-nilai muamalah tersebut.

2) Struktur Organisasi : Fungsi DPS mengawasi agar BMT dapat menjalankan prinsip syariah dengan baik dan benar, serta adanya pemisahan tugas (segregation of duty) yang jelas, terutama pada fungsi-fungsi yang berkaitan langsung dengan risiko finansial, seperti pada unit kerja pembiayaan dan pendanaan

3) Rencana Kerja Organisasi : Program kerja wajib disusun sebagai bagian dari rencana strategis BMT dalam mencapai target-target jangka pendek (tahunan) dan jangka panjangnya (lebih dari 1 tahun). Program kerja menjadi acuan BMT dalam menjalankan operasionalnya.

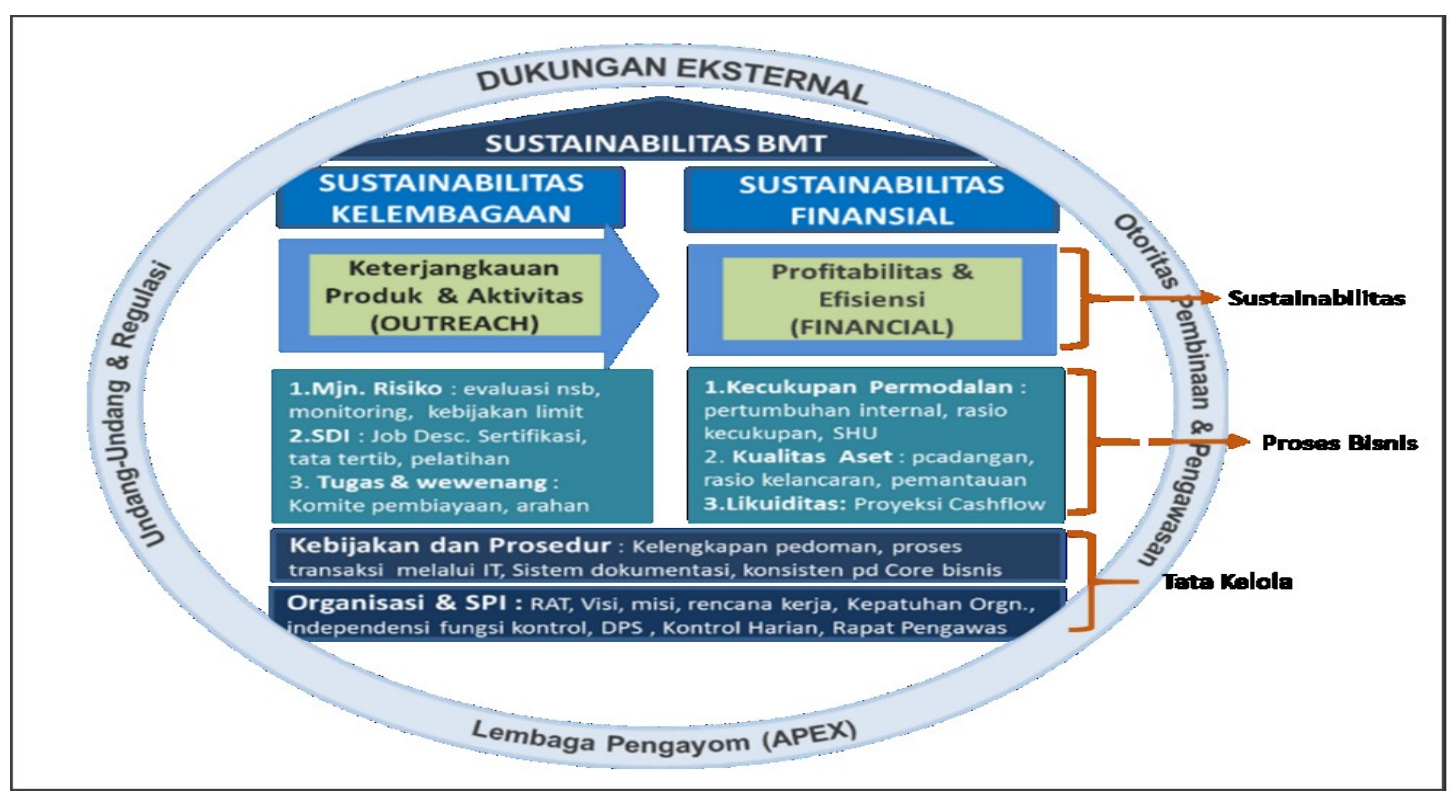

Gambar.1 Dukungan Eksternal

b. Kebijakan dan Prosedur

1) Integritas Proses Bisnis : BMT selaku mudharib harus dapat mengelola dana yang dipercayakan oleh masyarakat dengan hati-hati, baik dari operasional transaksi, kepatuhan terhadap pemenuhan seluruh ketentuan internal, eksternal dan standart yang berlaku, serta konsisten dalam menerapkan prinsip dan nilai-nilai syariah.

2) Kelengkapan Pedoman dan Prosedur : Penerapan sesuai pedoman akan menjamin adanya transparansi dan akuntabilitas suatu transaksi dan kegiatan operasonal lainnya. Kewenangan tanpa adanya pedoman dan prosedur operasional yang lengkap akan mendorong terjadinya confllict of interest atau penyalahgunaan wewenang dari pejabat pemegang kewenangan.

3) Konsistensi pada Core Bisnis : Perlu adanya kebijakan internal yang membatasi kegiatan investasi agar tidak menyimpang dari bisnis inti BMT. Seperti investasi pada bidang properti yang bukan untuk tujuan mendukung operasional BMT.

c. Sistem Pengendalian Intern

1) Manajemen Pengawasan : Dalam perspektif Islam pengawasan melekat dimulai dari diri sendiri, Meskipun telah ada pengawasan melekat, BMT harus tetap melakukan pengawasan berkala oleh petugas yang khusus menjalankan fungsi pengawasan.

2) Penegakkan Disiplin Kerja : Penegakkan disiplin kerja merupakan bagian dari sistem pengendalian intern, 
maka perlu adanya kebijakan mengenai penegakkan disiplin yang berakibat pada pengenaan sanksi. Penegakkan disiplin kerja harus transparan dan konsisten serta adanya mekanisme pengenaan sanksi tersebut.

\section{Proses Bisnis}

Setelah adanya pondasi yang kuat berupa tata kelola yang baik, maka perlu dilanjutkan dibangun proses bisnis yang handal dalam menjalankan operasional BMT sehari-hari, yaitu sebagai berikut :

a. Sumber Daya Insani (SDI)

1) Kebijakan Umum SDI : Perlu adanya infrastrukur SDI seperti : kesempatan yang sama dalam berkarir, tersedianya job description, tersedia kode etik dan tata tertib pegawai, tersedianya sarana dan kondisi kerja yang mendukung.

2) Standarisasi SDI : Aadanya perencanaan program jangka menengah-panjang untuk meningkatkan kualitas SDI agar tercapai kualifikasi dan standar kompetensi yang dibutuhkan BMT guna menjaga kepercayaan masyarakat dan kreditur.

3) Pengembangan dan Pelatihan SDI : Sasaran utama pengembangan dan pelatihan adalah agar pegawai memiliki pengetahuan operasional lembaga keuangan syariah secara baik, serta memiliki moral dan etika Islam yang tinggi.

b. Tugas dan wewengan

1) Kewenangan Memutus : Pada prinsipnya kewenangan memutus pembiayaan berada pada pengurus, namun agar pengambil keputusan mendapat pandangan atau review yang lebih obyektif dan lengkap terhadap nasabah pemohon, maka kewenangan memutus tersebut harus dalam koridor komite pembiayaan.

2) Pendelegasian Wewenang : Untuk meningkatkan efektifitas proses persetujuan pembiayaan, maka dapat dilakukan pendelegasian wewenang secara berjenjang kepada pejabat yang lebih rendah dalam struktur organisasi berdasarkan kebijakan pembiayaan yang ada.

3) Koordinasi dan Transparansi : Adanya koordinasi secara berkala dari pengurus paling tidak satu kali dalam sebulan untuk memberikan arahan bisnis maupun non bisnis kejajaran BMT. Aspek transparansi, antara lain pengurus secara berkala memberikan laporan atau rapat koordinasi dengan pengawas mengenai rencana keputusan dan atau keputusan, kendala dan permasalahan yang dianggap signifikan.

c. Manajemen risiko pembiayaan.

1) Evaluasi Nasabah : adanya evaluasi nasabah yang mencakup : Character, Capital, Capacity, Collateral dan Condition of Economic atau dikenal sebagai prinsip 5'C.

2) Kebijakan Limit : Kebijakan penetapan limit merupakan bagian dari pengelolaan risiko, dimana besarnya limit risiko disesuaikan dengan pengalaman BMT dan tingkat risiko yang akan diambil (risk appetite).

3) Segregation of Duty atau Four Eye Principle : Pemisahan tugas dan kewenangan pada pembiayaan adalah untuk menjamin proses pembiayaan dilaksanakan secara independen sesuai dengan job description masing-masing unit kerja.

d. Meningkatkan Keterjangkauan Produk dan Aktivitas

1) Aksesbilitas dan layanan (Outreach) : Aksesbilitas dan layanan dalam menjangkau pasar (Outreach) menjadi indikator utama pencapaian sustainabilitas dan keberhasilan kinerja BMT baik secara kelembagaan, finansial maupun fungsi dalam menjalankan inklusif sektor keuangan nasional..

2) Membangun sinergi dan pendampingan BMT dapat berperan menjalankan fungsi pembinaan atau pendampingan dalam rangka pemberdayaan angota atau nasabahnya, membangun jaringan atau sinergi bisnis dengan anggota 
lainnya yang memiliki keterkaitan usaha dan mempercepat proses pemberdayaan anggotanya agar terus meningkat kesejahterannya.

3) Menjalankan fungsi sosial melalui peran aktif BMT tersebut diharapkan sasaran zakat sebagai media pemberdayaan umat dapat tercapai, yaitu merubah mustahiq (penerima zakat) menjadi muzakki (pembayar zakat).

e. Kinerja finansial

1) Kecukupan Permodalan : BMT sebagai lembaga keuangan harus selalu mengupayakan adanya dukungan permodalan yang kuat dari anggota, sebagai penggerak utama perputaraan usaha BMT.

2) Kecukupan Likuiditas : Tujuannya agar tidak terjadi kekurangan likuiditas (shortage liquidity) atau kelebihan likuiditas (over liquid) dan memastikan kecukupan likuiditas dalam menjalankan operasionan sehari-hari.

3) Kualitas Aset : Kualitas aset harus benar-benar dijaga dan dikelola dengan baik, yaitu mulai pemilihan sektor usaha yang prospektif, seleksi awal nasabah, kualitas evaluasi nasabah, pemenuhan syarat nasabah, monitoring dan penagihan hingga pelunasan kembali pembiayaan..

4) Profitabilitas dan Efisiensi : Profitabilitas menjadi indikator utama sustainabilitas keuangan, dimana perolehan profitabilitas merupakan muara dari hasil dari pengelolaan Aset, liabilitis dan risiko dari BMT.

\section{Lingkungan Industri yang Mendukung (Dukungan Eksternal)}

a. Undang-Undang dan Regulasi : Adanya Undang-Undang yang dapat melindungi dan mendukung keberadaan Lembaga Keuangan Mikro Syariah, serta koordinasi pengaturan dan tata kelola pada tingkat makro secara lintas instansi, Undang-Undang yang ada saat ini belum konkrit keberpihakannya terhadap Lembaga Keuangan Mikro Syariah.

b. Otoritas Pengawasan : BMT sebagai lembaga keuangan wajib menerapkan prinsip kehati-hatian dalam menjalankan kegiatan usahanya, dengan demikian perlu adanya otoritas pengawas yang melakukan supervisi. Adanya otoritas pengawas ini mendorong industri BMT kearah yang lebih sehat dan sustain.

c. Lembaga Pengayom (APEX) : Adanya kebersamaan sesama BMT dalam rangka membangun lembaga pengayom, utamanya untuk mengantisipasi kendala-kendala internal industri BMT yang dihadapi, seperti masalah likuiditas atau sumber pendanaan, jaringan transaksi, jaringan program (linkage program), meningkatkan kapasitas teknis dan manajemen, pengembangan dan pelatihan SDI, sertifikasi kompetensi, penyusunan standar moral dan etika, permodalan hingga menampung dan menyalurkan aspirasi kepada otoritas atau regulator.

\section{SIMPULAN}

Berdasarkan hasil analisis dan dapat ditarik kesimpulan sebagai berikut:

a. Sustainabilitas Kelembagaan akan membentuk Outreach, yaitu skala jangkauan operasional BMT yang luas dan fleksibel melalui berbagai produk dan laya" nan jasa keuangannya untuk masyarakat. Sustainabilitas Keuangan merupakan kondisi dimana operasional BMT pada posisi yang menguntungkan dan efisien.

b. Tata Kelola yang Baik (Good Governance), yaitu memiliki organisasi yang sehat, didukung oleh sistem pengendalian internal, serta adanya kebijakan dan prosedur yang memadai dan proses transaksi dan pelaporan melalui sistem IT yang aman.

c. Proses bisnis yang handal, yaitu didukung oleh sumber daya insani yang memiliki kompetensi dan dilengkapi dengan tugas dan kewenangan yang jelas, serta menjalankan proses manajemen risiko pembiayaan yang memadai. 
d. Mencapai sustainabilitas keuangan, yaitu dengan kecukupan permodalan yang dipenuhi dari internal, menjaga kualitas aset dan pembentukan cadangan, serta melakukan proyeksi dan pemantauan likuiditas.

e. Menciptakan lingkungan industri yang mendukung, antara lain mendorong pemerintah dan regulator untuk menerbitkan undang-undang dan peraturan yang berpihak kepada lembaga keuangan mikro, serta pembentukan lembaga pengayom (APEX) untuk memperkuat aspek likuditas dan manajemen BMT.

Bagi pelaku BMT perlu mengimplementasikan faktor-faktor operasional yang terdapat pada aspek tata kelola (good governance) dan proses bisnis, agar tercapai tujuan utama sustainabilitas BMT berupa keterjangkauan produk dan akvitas (Outreach) serta tingkat keuntungan yang memadai (financial) sebagaimana diuraikan pada hasil.

\section{DAFTAR PUSTAKA}

Antonio, Muhammad Syafi'i, 2001, Bank Syariah dari Teori ke Praktik, Gema Insani Press

Arsyad, Lincolin PhD, 2008, Lembaga Keuangan Mikro : Institusi, Kinerja dan Sustainabilitas, ANDI Yogyakarta

Azis Abdul, 2008, Ensiklopedia Etika Islam, Begini Semestinya Muslim Berperilaku, Maghfirah Pustaka

Az- Zuhaili, Prof. DR. Wahbah, 2011, Fiqih Islam \&: Sistem Ekonomi Islam, Pasar Keuangan, Hukum Hadd Zina, Qadzf, Pencurian, Gema Insani

Bank Panin Syariah PT. 2014. Bank Panin Syariah dan APEX BMT : Model Bisnis (Perbankan Tanpa Cabang)

Bank Indonesia, 2011. SE 13/23 Surat Edaran : Penerapan Manajemen Risiko bagi Bank Umum

Banker Association for Risk Management (BARa), 2012, Modul Level 2 Uji Kompetensi Profesi Bankir bidang Manajemen Risiko

Crescent Tim, 2003, Mепuju Masyarakat Mandiri, Pengembangan Model Sistem
Keterjaminan Sosial, PT. Gramedia Pustaka Utama

Haroen, Dr. H. Nasrun MA, 2007, Fiqih Muamalah, Gaya Media Pratama Jakarta

Hakim, Lukman, 2012, Prinsip-Prinsip Ekonomi Islam, PT. Gelora Aksara Pratama, Penerbit Erlangga

Ikatan Bankir Indonesia, 2014, Memahami Bisnis Bank Syariah, PT. Gramedia Pustaka Utama

Karim, Ir Adiwarman Am Sem MBA, MAEP, 2010, Bank Islam Analisa Fiqih dan Keuangan, PT. RajaGrafindo Persada

Ledgerwood, Joane dan Earnie, Julie, 2013, "The New Microfinance Handbook: A Financial Market System Perspective" World Bank

Mundalus, Karlena, Yohanes, Credit Union : Kendaraan Menuju Kemakmuran, PT. Elex Media Komputindo, Jakarta

Otoritas Jasa Keuangan, 2017. SEOJK No. 14/SEOJK.03/2017 Surat Edaran : Penilaian Tingkat Kesehatan Bank

Otoritas Jasa Keuangan, 2017. SEOJK No. 13/SEOJK.03/2017 Surat Edaran : Penerapan tata kelola.

Otoritas Jasa Keuangan, 2016. POJK No. 65/POOJK.03/2016 Surat Edaran : Penerapan tata kelola.

Prabowo, DR Hayu S. 2015. Ilmu Ekonomi dan Keuangan Islam : Indonesia Banking School

Ridwan Muhammad, 2014, Manajemen Baitul Maal wa Tamwil (BMT), UII Press Yogyakarta

Salam, Dr Abdul, 2008, Sustainabilitas Lembaga Keuangan : Koperasi Simpan Pinjam, Sekolah Pascasarjana UGM.

Santoso Singgih, 2006, Statististik Di Era Informasi dengan SPSS 14, PT. Elex Media Komputindo, Jakarta

The Indonesian Association of Islamic Economist (IAEI). 2013. Forum Riset Perbankan Syariah VI tahun 2013

Trihendradi C, 2013, Step By Step IBS SPSS 21 : Analisa Data Statistik, ANDI Yogyakarta). 